$$
\text { Conflimente of the tuther- }
$$

\title{
THE STEWARD OBSERVATORY OF THE UNIVERSITY OF ARIZONA
}

A. E. DOUGLASS

DECEMBER, 1918

(Reprinted from the Publications of the Astronomical Society of the Pacific,

No. 178 , December, 1918 ) 


\section{THE STEWARD OBSERVATORY* OF THE UNIVERSITY OF ARIZONA}

\section{A. E. Douglass}

In I9I6 the late Mrs. Lavonia Steward of Tucson, made a gift of $\$ 60,000$ to the University of Arizona for the purpose of erecting an astronomical observatory, as a memorial to her late husband, Mr. Henry B. Steward, who had died in Tucson. In this generous act she showed, not only her interest in the University and a firm confidence in its future, but also a long cherished love for the oldest of sciences, and an appreciation of the beautiful skies of the Southwest.

After careful study of the subject, a reflecting type of instrument was decided upon with simple housing, which in Southern Arizona can be reduced to a minimum. The large telescope was to be supported by smaller instruments and various accessories. A contract for a 37 -inch reflector mounting was entered into with Warner and Swasey, and the instrument was expected to be ready for work on Mars in the opposition just passed. But the war intervened and work on the mounting was postponed. This delay in the construction of this chief instrument makes very desirable the construction of the essential parts of the building, so that the observatory may become a tangible reality, and in spite of greatly increased cost of materials, we expect to have at least the nucleus of the observatory buildings erected in the immediate future.

\section{LOCATION}

The City of Tucson, in which the University of Arizona is located, is a town of some 16,000 or I 8,000 people of which a portion is Spanish-American. Two railroads enter the town, the Southern Pacific and the El Paso and Southwestern. Tucson is the site of the Carnegie Desert Laboratory, and a Magnetic Observatory of the U. S. Coast and Geodetic Survey. The well known San Xavier Mission built about $\mathrm{I} 792$ is ro miles south.

The City of Tucson, with the University, is located in the midst of a large flat valley or bolson, having a gentle slope toward the Santa Cruz wash, which in turn, flows north along the western side of the valley floor. The University is about two miles east of the wash, and high enough above it to escape most of the down-flow

${ }^{*}$ Read before The American Astronomical Society, Aug. 20, I918, at Cambridge, Mass. 
of cold air at night. The surrounding mountain ranges are the Catalinas, 20 miles to the north, the Santa Ritas, 30 miles southeast. and the low ranges of the Tucson mountains, some ro miles west, The elevation is 24,00 feet. Thus it is everywhere surrounded by mountains with altitudes of one-half of a degree up to four or five degrees, except at a point in the south where the apparent horizon is about four feet above the true horizon, and in the northwest, where the apparent horizon is actually some 20 feet below the true horizon.

Climatically the winters are mild, with snow once in three or four years, and remarkably free from cloud; the spring and autumn have prolonged cloudless periods, and the summers are less subject to thunderstorms than higher elevations. In this region the rainfall and cloudiness increase rapidly with elevation. Fog is practically unknown. The latitude is $32^{\circ} \mathrm{I}^{\prime}$ north and the longitude III ${ }^{\circ}$ west ( 7 hours 24 minutes). The average rainfall is close to $\mathrm{I} 2$ inches and the surrounding country is covered with a desert vegetation, of which the giant cactus, or Seguara, is a very characteristic feature.

But combined with the clearness that goes with a favorable situation in a dry region, is another very important factor, namely freedom from wind, especially at night. This is due to the general situation in the "Horse Latitudes," the protection of the mountains, and the fact that the slope of the valley is slight, and the outlet in a northwesterly direction.

The question as to whether a location on the campus of the University would be satisfactory, compared with the nearest hill three miles to the west, was made the subject of a careful study. In clear countries where the winds are not strong, cold air settles in the valleys at night, and flows downward like streams of water. If this layer is very much colder than the layer of air immediately above it, the mixture of the two causes a tremulousness of the star images which greatly interferes with fine-definition. In order to test this, a four-inch telescope was placed on the hill, and a series of simultaneous observations made there and on the campus. The average condition of the atmosphere over the hill was 8 on a scale of Io, and at the University about 7.8. From numerous trips across the valley late at night, the main flow of cold air was found to be chiefly in the vicinity of the Santa Cruz wash. The flow at the University is usually a gentle working of the air from the uplands in the southeast toward the general outlet of the valley. The effects 
of the cold air were small, and it was estimated that a location on the campus might sacrifice 5 or Io per cent of atmosphere conditions when compared with the neighboring hill.

On the other hand the difficulties of locating an observatory on the hill are very great on account of the added expense in roads, buildings, water, power and light, and on account of the greater distance from town and living accommodations. These features tend toward diminished efficiency and seem to offset the occasional slight improvement in atmospheric conditions.

In choosing a point on the campus, the following items were considered:

Direction of night winds.

Heated air from buildings.

Smoke and heat from power plant.

Clear horizon.

Temperature changes at night.

Campus light.

Also the practical items:

Accessibility.

Landscape and gardening effect.

Freedom from unnecessary stairs.

A large telescope is extraordinarily sensitive to minute changes in the air temperature. The heated air from a large building carried across the campus by the prevailing wind is evident some hundreds of feet away. Temperature changes at night are of the greatest disadvantage in modern astrophysical work. The lights surrounding the observatory need the most careful regulations. For instance, the photography of extremely faint objects like the zodiacal light had been found impossible on top of the Science Building in the lighted campus while not at all difficult well outside. A place was therefore selected in the new and unoccupied part of the campus to the east, which is also slightly higher than any other part, and recommendations made that the University avoid the erection of large buildings in that vicinity and especially to the south and east, and that the campus lights be under the control of the astronomer in charge.

Type of Instrument

The type of chief instrument for the Observatory was a subject of extended study. My thanks are due to many astronomers for 
their counsel and experience, but perhaps especially to Dr. Hale for permission to try out the 6o-inch reflector on Mount Wilson. I had made tests on the planet Mars, with which I was very familiar, in the Snow telescope (24-inch reflector) with very unsatisfactory results, but the astronomers in charge asserted that it was not a fair test as the instrument had been used that day on the Sun and temperature effects were still in the glass, distorting its shape. However, after using the I6-inch Mount Lowe Clark refractor on Mars for several weeks, I visited the Mount Wilson Observatory and had some hours with the 6o-inch on a superb night, and had the best view of Mars it has ever been my good fortune to behold. The 6o-inch is guarded, most carefully, against temperature changes.

The truer color values in the reflector also are important. I have long had the feeling that the colors seen in the dark markings of Mars are strongly affected by the chromatism of the objective. Deciding factors in the question of type of instrument also were the probable years of delay before proper optical glass for an objective could be obtained, and the difference in cost.

\section{BUILDING}

Plans are now being drawn for a compact fireproof concrete building, to provide support and covering for the telescope and such rooms as may conveniently be put in it. These will include photographic, silvering, store, sleeping and exhibit rooms, and office. The top will be the observing floor, which can be used temporarily for the 8-inch telescope. Some minimum yet effective type of covering is now being devised, which will have most of the sky exposed, as in the present arrangement for the 8-inch. It is expected that extensive additions will be made at a later date.

\section{Operation}

The working plans of an observatory whose chief instrument is delayed by a great and necessary war must certainly be much curtailed. Nevertheless, important work can be done. The time of the director has been largely freed from class-room work, and will be devoted to research. We have in use a very excellent 8-inch telescope, loaned us in I9o9 by the courtesy of Professor E. C. Pickering. This has been used extensively in work on Mars and on Jupiter's satellites, and to some extent on variable stars, and on atmospheric studies, as well as in continuous work with classes. 
Add to these also a 4-inch telescope, belonging to the University, a 3-inch and a small portable astronomical transit belonging to the writer. A Callender Sunshine Receiver with a Leeds and Northrup recording mechanism, has been in operation since October, I9I3. The records have only been partly reduced, and they contain a large amount of valuable material, one of whose possibilities is a check on large solar variations. For standardizing this, we have a Smithsonian silver disk pyrheliometer. There is also a special zodiacal light camera with which the writer can renew a series of photographs of the light, begun by him in I90I, and continued in I9I5. The writer is extensively engaged in a study of the relation between tree growth as shown in the annual rings, terrestrial weather and solar activity.

It is the most earnest wish of the writer that the Steward Observatory shall be a productive observatory, and that the instrument when it comes shall not be merely for sight-seeing. Professor Campbell, who usually hits a vital point, wrote us some time ago:

"A new observatory should start with an equipment designed for productive work in the immediate future, and further development of the institution should follow along evolutionary lines to meet definite requirements as they are foreseen; any other plan is likely to lead to the founding of a museum rather than an observatory."

There is not any line of astronomical research in which we do not have the best of opportunities in the matter of weather. Especially everything that needs daily or nightly work will be in our special province. In this manner, I hope that the Steward Observatory will fulfil the wishes of the lady who gave it, and be a credit to the State of Arizona. 